A few weeks ago, I was looking out the window of my Reykjavik hotel room wearing my corduroy jacket and kilt, watching workmen laying underground drainage while talking on the phone to my son about roofing his garage with PVC sheeting. While I was watching, a car collided with the one ahead of it, but luckily no one was hurt. As I put the phone down, my wife looked up from her task of wrapping a present (a print of a beautiful butterfly in a ploughed field) in bubble wrap and cardboard. As I strolled toward the bathroom, I noticed that the door was damaged, and I could see the paper honeycomb, which separated the two veneer panels (it was a cheap hotel). When I emerged, we discussed the potential benefits, or otherwise, of the latest anti-wrinkle cream-for both of us, I hasten to add before my wife reads this.

Being a materials scientist, instead of thinking ahead to the organ concert in Hallgrimmskirke booked for the evening or back to the whales we had watched that morning, I thought, as I'm sure you would have, "corrugations" and then "gratings!" Come to think of it, the whales probably had corrugations, too, but they did not throw themselves far enough out of the water for us to see them or open their mouths wide enough for me to resolve the baleen grating.

The observation that triggered this train of thought was that many buildings in Iceland use "corrugated iron" for their roofs and walls. Apart from making a lot of noise in the rain, galvanized steel has some excellent properties for use in buildings. When corrugated, it has high stiffness in one direction, and is thin and cheap. But in Iceland, they usually paint it, often in a bright color. This is presumably for architectural impact not for corrosion protection; however, my observation is that on most corrugated roofs and walls, the paint was peeling, whereas almost none were rusting. The effect of the coat of paint was therefore to make most buildings look scruffy and inelegant while offering near-zero additional corro-

\section{Making Waves}

sion protection. A victory of form over function? I am surprised that pre-coated, and thus colored, galvanized steel is not used more, but then I live only a few miles from UK's main coil-coating plant at Shotton.

My corduroy jacket, pleated kilt and the ploughed field simply reinforced the ubiquitous and commonplace appearance of corrugations. (Isn't it a lovely word designed to be pronounced by a French voice with the r's rolled?)

Being a materials scientist,
instead of thinking ahead to the
organ concert in Hallgrimmskirke
booked for the evening or back to
the whales we had watched that
morning, I thought, as I'm sure
you would have, "corrugations"
and then "gratings!"

Under the roads, the workmen were laying flexible polymeric pipes, corrugated into the familiar bellows-like shape (and not, I'm sure, painted). My handset was connected to the telephone by a spiral cord, again designed for flexibility, but this time prone to tangling. At some point in its journey to my son, the telephone signal probably passed through an antenna with a corrugated horn.

The car occupants escaped serious injury from their accident because of the presence of energy-absorbing corrugated tubing in their crumble zones. Our faces potentially had their wrinkles removeda sort of anti-corrugation-by a cream that presumably shrinks the skin, lowering the total surface area.

Which brings us to bubble wrap, which is not itself corrugated but has replaced that lovely product "corrugated cardboard." Bubble wrap is to corrugated cardboard as quantum dots are to quantum wires (but easier to handle). Bubble wrap can, of course, be wrapped in any direction and folded along any axis, as opposed to the single easy-fold axis of corrugated cardboard. Bubble wrap is therefore good for packing but less good for making structures and much less easy to glue together. Nowadays, when we set students the task of making a loadbearing structure out of card or paper, they have to resort to folding in order to design in some compressive strength or stiffness. But folding does not work for the fabric of my pleated kilt, which drapes well over any shape, even my knobbly knees.

There is no single easy-fold axis for a honeycomb structure. This is fine for a flat structure such as a door but less good for curved forms. It is well known that a thin honeycomb will, if bent about one axis in its plane, spontaneously bend in the opposite direction about the orthogonal direction. This forms a col (or saddle shape) and cannot be persuaded to cover a convex shape, such as the end of a submarine. For this we need an auxetic honeycomb with a negative Poisson rate. It is nice to see that this terminology has made it into Wikipedia, so you can check me on this one.

So corrugations are everywhere-flat materials are so last year (or do I mean last century?). Lots of challenges remain: Has anyone made an auxetic steel sheet yet? Why was corrugated steel called "wriggly tin?" Tin? Why are the corrugated "rumble strips" on roads so irritating? Do you even have them in other parts of the world? Will "box-profile" PVC sheet ever take over from the conventional "sine-wave" sheet? If so, why? I could go on, but my thousand words are almost up.

Okay, so the kilt was an exaggeration. I'm English and not given to wearing skirts. And the butterfly? Crossed gratings giving moiré fringes. Now I'm going off to contribute to that well-known interactive online soap opera "Corrugation Street" (really!).

Peter GoOdHEW 